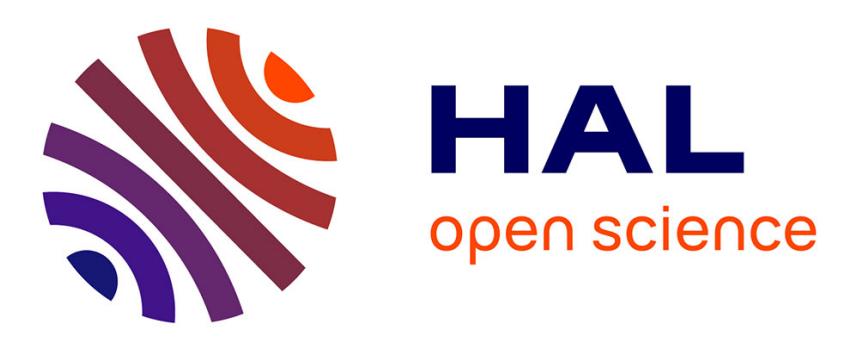

\title{
Reducing stress during welfare inspection - Validation of a non-intrusive version of the laywel plumage scoring system for laying hens
}

Joergen Kjaer, Henrike Glawatz, Britta Scholz, Sophie Rettenbacher, Ragnar Tauson

\section{To cite this version:}

Joergen Kjaer, Henrike Glawatz, Britta Scholz, Sophie Rettenbacher, Ragnar Tauson. Reducing stress during welfare inspection - Validation of a non-intrusive version of the laywel plumage scoring system for laying hens. British Poultry Science, 2011, 52 (02), pp.149-154. 10.1080/00071668.2011.554799 . hal-00686679

\section{HAL Id: hal-00686679 https://hal.science/hal-00686679}

Submitted on 11 Apr 2012

HAL is a multi-disciplinary open access archive for the deposit and dissemination of scientific research documents, whether they are published or not. The documents may come from teaching and research institutions in France or abroad, or from public or private research centers.
L'archive ouverte pluridisciplinaire HAL, est destinée au dépôt et à la diffusion de documents scientifiques de niveau recherche, publiés ou non, émanant des établissements d'enseignement et de recherche français ou étrangers, des laboratoires publics ou privés. 


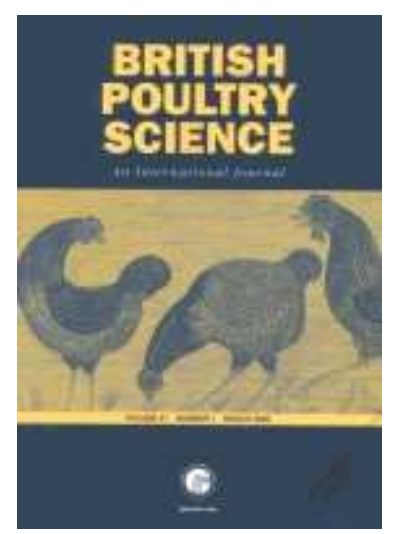

\section{Reducing stress during welfare inspection - Validation of a non-intrusive version of the laywel plumage scoring system for laying hens}

\begin{tabular}{|c|c|}
\hline Journal: & British Poultry Science \\
\hline Manuscript ID: & CBPS-2010-041.R3 \\
\hline Manuscript Type: & Original Manuscript \\
\hline $\begin{array}{r}\text { Date Submitted by the } \\
\text { Author: }\end{array}$ & 16-Aug-2010 \\
\hline Complete List of Authors: & $\begin{array}{l}\text { Kjaer, Joergen; Friedrich-Loeffler-Institut, Institute for Animal } \\
\text { Welfare and Animal Husbandry } \\
\text { Glawatz, Henrike; FBN Dummerstorf, Fachbereich Genetik und } \\
\text { Biometrie } \\
\text { Scholz, Britta; Friedrich-Loeffler-Institut, Institute for Animal } \\
\text { Welfare and Animal Husbandry } \\
\text { Rettenbacher, Sophie; University of Veterinary Medicine, } \\
\text { Biochemistry, Department of Biomedical Sciences } \\
\text { Tauson, Ragnar; Swedish University of Agricultural Sciences, } \\
\text { Animal Nutrition and Management }\end{array}$ \\
\hline Keywords: & $\begin{array}{l}\text { Behaviour, Welfare, Feather pecking, Laying hens, Physiology, } \\
\text { Stress }\end{array}$ \\
\hline
\end{tabular}

\section{SCHOLARONE \\ Manuscripts}


1

2

3

4

5

6

7

8

9

10

11

12

13

\section{Reducing stress during welfare inspection: validation of a non-intrusive version of the} LayWel plumage scoring system for laying hens

4 KJAER, J. B., GLAWATZ, H., SCHOLZ, B., RETTENBACHER, S. AND TAUSON, R. 5

6 Friedrich-Loeffler-Institut, Institute for Animal Welfare and Animal Husbandry,

7 Dörnbergstrasse 25-27, D-29223 Celle, Germany

8 9 10

14 Correspondence to: Dr Joergen B. Kjaer, Friedrich-Loeffler-Institut, Institute for Animal

15 Welfare and Animal Husbandry, Dörnbergstrasse 25-27, D-29223 Celle, Germany.

16 Telephone +495141 384612; Fax +4951413846117

17 E-mail: joergen.kjaer@ fli.bund.de
Running title: Reducing stress during welfare inspection

Accepted for publication: 24th Aug 2010 
20 Abstract. 1. The objectives of the present study were to validate a reduced, non-intrusive

21 version (RLS) of the LayWel plumage scoring system in domestic laying hens with reference 22 to complete, intrusive scoring (CLS) and to investigate the effect of these two scoring 23 methods on corticosterone metabolite concentrations.

24 2. A total of 312 medium-heavy laying hens from 4 commercial hybrids kept in 24 floor pens 25 were scored by two experienced teams. Another 150 hens from two hybrids kept in 6 pens 26 were used for estimating scoring treatment effects on corticosterone metabolites in droppings.

27 3. Plumage scores were in general higher using the RLS method compared to the CLS 28 method. The agreement between teams for plumage scores (CLS) were on a high (total score) 29 to an excellent (single body part except breast and cloaca) level.

30 4. Birds subjected to CLS tended to have higher concentrations of corticosterone metabolites 31 in droppings $2 \mathrm{~h}$ after scoring compared with birds in the control treatment (not scored). Birds 32 subjected to RLS had intermediate concentrations.

33 5. It was concluded that a reduced version of the LayWel scoring system is a valid and 34 reliable scoring method which tends to induce less stress to the subjects than the original 35 procedure. 
37

38 Animal welfare inspection of laying hen flocks often includes the evaluation of plumage

39 condition which is considered to be an indirect measure of the amount of feather pecking in

40 the flock (Hughes, 1982). Such scoring systems are important since recording the incidence of

41 feather pecking in a flock by direct observation is difficult and very time consuming. Several

42 methods of plumage scoring have been used, however, for practical reasons, subjective

43 scoring is by far the most common method. The methods are classified as (i) application of a

44 general score for the plumage of the whole body (Hughes and Duncan, 1972; Hill, 1980) and

45 (2) application of a specific score for individual parts of the body (Tauson et al., 1984;

46 Gunnarsson et al., 1995; Abrahamsson, 1996; Kjaer, 2000; Gunnarsson, 2000; Tauson and

47 Holm, 2003). In the LayWel EU-project (LayWel, 2005) it was concluded that meta-analysis

48 of plumage data was difficult due to the use of several different scoring systems. Hence a new

49 practical system based on the scoring of several body parts was proposed as a standard to use

50 in future research (Tauson et al., 2005; 2007).

51 This new system involves the capture and handling of individual birds, which are

52 scored for plumage condition on 6 parts of the body (neck, breast, back, wings, cloaca/vent

53 and tail) along with scores for pecking damage to the rear of the body and comb, keel bone

54 deviations and bumble foot lesions. Scores of 1-4 are awarded with higher scores indicating

55 better condition of the integument. The system can be used to compare the incidence of scores

56 1-4 for individual body parts, or the scores can be pooled to give a whole body score ranging

57 from 6-24. In the present study, we considered only the plumage condition element of the

58 scoring system, which we refer to as the 'complete Laywel plumage scoring system' or CLS.

59 Scoring systems should be (1) simple to apply and allow for good repeatability

60 (Tauson et al., 1984), (2) impose as little disturbance to the birds as possible, and (3) be time-

61 effective, enabling the user to score a large number of birds under commercial conditions in a 
62 short period of time, and without stressing the birds. Capture and handling are stressful

63 procedures which can raise plasma corticosterone concentrations within minutes (Kannan and

64 Mench, 1996). In addition, capturing a representative sample in floor or free range systems

65 can be difficult and there are potential risks of sampling errors. CLS fulfils the requirements

66 of the first criterion, but not the second and third. We therefore developed a reduced version

67 of the LayWel scoring system (RLS) by introducing two major changes: (1) scoring only 4

68 body parts (neck, back, wings and tail) and (2) scoring birds on the ground without catching

69 and handling birds at any point. To our knowledge, no results from objective recording of

70 physiological stress variables after a combination of catching, handling and plumage scoring

71 have yet been published. We therefore assessed adrenocortical activity non-invasively (by

72 quantifying corticosterone metabolites in the droppings) after scoring, comparing values

73 obtained with these two scoring methods with concentrations of un-scored controls.

74 Thus, the objectives of the present study were to (1) validate the reduced, non75 intrusive version of the LayWel plumage scoring system in domestic laying hens (Gallus 76 gallus domesticus) with reference to the complete, intrusive scoring, and (2) to investigate the 77 effect of these two scoring methods on corticosterone metabolite concentrations.

78 79

\section{Animals, housing and management}

81 A total of 1100 non-beak-trimmed chickens of 4 hybrid strains (ISA Warren (IW), Lohmann 82 Brown (LB), Lohmann Tradition (LT) and Tetra SL (TS)) were reared on litter floor and 83 housed at 16 weeks in 44 (11 per breed) partly (2/3) slatted floor pens (1.15 m wide x $4.10 \mathrm{~m}$ 84 long) at a stocking density of 6 hens per $\mathrm{m}^{2}$ ( 25 hens per pen) and with a communal nest at the 85 rear of the pen. Layer mash (200 g CP/kg, 11.2 MJ ME/kg feed) and water were supplied $a d$ 86 libitum. A 14L:10D light programme was applied with an approximate light intensity of 15 
87 lux. The hens were part of an experiment investigating the design of 'on farm' performance

88 tests of laying hen hybrids for organic egg production.

89

\section{Data collection}

$91 \quad$ Plumage scoring

92 Plumage condition of 312 hens was scored at the age of 73 weeks by two teams, each 93 consisting of two scorers and one assistant. Both teams scored the same 13 hens from each of 9422 randomly chosen pens ( 6 per breed of LB and LT, 5 pens per breed of ISA and TB). The 95 practical scoring procedure consisted of the following steps:

96 (1) All hens were shepherded gently to one half of the pen and kept there by dividing it with a 97 catching frame made of steel and wire netting.

98 (2) Hens were separated by an assistant and individually guided through an opening to the 99 other half of the pen, while the scorers were standing nearby $(2-3 \mathrm{~m})$ scoring (blind to the 100 other scoring team) and recording the scores on paper (RLS method, see below).

101 (3) The assistant then caught, marked and crated the hen that had just been scored. Blue dye 102 marks on the legs enabled the second team to identify and score the same birds previously 103 scored by the first team, in order to produce independent scores by both methods on each bird. 104 The second team thus produced a CLS score blind to the RLS score given by the first team.

105 (4) After scoring, birds were immediately released back into the pen, thus avoiding the risk of 106 recapture.

107 The Complete LayWel Plumage Scoring System (CLS) is described in the 108 Introduction. Supplementary material with colour illustrations is available at the LayWel 109 homepage (LayWel, 2005) and also in Tauson et al. (2007). In the present experiment, only 110 that part of the integument representing plumage quality was used and validated and this 111 system will be called the 'complete LayWel plumage scoring system' (CLS). 
113 (1) scoring only 4 body parts, neck, back, wings and tail, and (2) scoring birds on the ground 114 without catching and handling birds at all. The scorer stood outside the pen during the 115 scoring, thus minimising disturbance.

116 No scoring was carried out in the control treatment (CON) and no humans stood in 117 front of the pen. Only normal animal care, as practised in the other pens in the house, was 118 permitted.

\section{Measurement of corticosterone metabolites}

121 Three pens of LB and three pens of LT hens, not previously scored for plumage condition, 122 were used to investigate the effect of scoring method and genotype on stress hormone 123 metabolites. One of three scoring methods was applied to each genotype: CLS, RLS or CON. 124 In CLS, all birds of a pen were caught and crated before scoring $30 \mathrm{~min}$ later. Birds were 125 scored while handled and released into the pen again. In RLS, the scorer went to the front of 126 the pen, opened the door and scored the birds individually from a distance; scoring time was 127 approximately 5 min per pen. In CON, there was no scoring or crating and no humans stood 128 in front of the pen. Excreta samples (consisting of faeces and urates together) were taken from 129 all hens in a pen beginning 120 min after initiation of the treatment. Excreta sampling lasted 130 approximately $20 \mathrm{~min}$ per pen. Only samples of adequate size $(>0.1 \mathrm{~g})$ from 86 out of a total 131 of 133 sampled birds were analysed. Samples were frozen at $-21^{\circ} \mathrm{C}$ until later analysis for 132 3,11-dione glucocorticoid metabolites, as described by Rettenbacher et al. (2004) using a 133 cortisone enzyme immunoassay previously validated for chicken excreta (Rettenbacher et al., 134 2009). Data were expressed as ng hormone equivalent per g excreta. 135 136 Statistical analysis 


\section{$137 \quad$ Plumage scoring}

138 For each combination of method (CLS, RLS) and scoring team (A, B), a total feather score

139 for each hen was calculated by summing the scores for each body region and then calculating 140 the average score per pen. This score had a minimum of 4 points $(1 \mathrm{p}$ per body part $\times 4$ body 141 parts) and a maximum of 16 points $(4 \times 4)$ for the RLS method, summing scores for neck, 142 back, wings and tail. For the CLS method, two sums were calculated; a partial sum used for 143 comparing methods was calculated exactly like for the RLS method, summing neck, back, 144 wings and tail. Further, a complete sum was calculated for testing repeatability of teams 145 within this method, summing neck, back, tail, wings, breast and cloaca, thus making the 146 maximum possible sum 24 points per hen.

147 Pen average plumage score was the statistical unit. Method (CLS, RLS), team (A, B), 148 the interaction between method and team, and genotype (LT, LB, TS, IW) were included as 149 fixed factors into a mixed model procedure in SAS (SAS Inst. Inc., Cary, Il, USA). Method 150 and team were included as repeated measures (Littell et al., 1996), and normal distribution of 151 residuals was accepted after visual inspection.

\section{Reliability of methods and teams}

154 The between-method and between-team reliability were estimated using several measures of 155 agreement, namely kappa, weighted kappa and prevalence-adjusted bias-adjusted kappa 156 (PABAK), since there is controversy as to the best statistic. The kappa statistic alone is 157 appropriate if the marginal totals for the $2 \times 2$ table are relatively balanced, but if the 158 prevalence of a given response is very high or low, the value of kappa may indicate poor 159 agreement even when the observed proportion of agreement is quite high. Therefore we also 160 present the prevalence-adjusted bias-adjusted kappa (PABAK) to more fully characterise the 161 extent of the agreement between the two methods and teams respectively (Byrt et al., 1993). 
162 The procedure FREQ of SAS was used to calculate kappa, asymptotic standard error, 163 standardised test statistic, the $P$ value for testing the two-sided hypothesis $\operatorname{Pr}>|\mathrm{T}|$, and 164 weighted kappa. A custom-written SAS-program was used to calculate PABAK, following 165 Cunningham (2009) and using the formula PABAK $=([k+p]-1) /(k-1)$, where $k$ is the number 166 of categories and $p$ the proportion of agreement. According to Fleiss et al. (1993), a PABAK 167 score larger than 0.40 can be interpreted as good agreement and a score larger than 0.75 as 168 excellent agreement.

\section{Hormone data}

171 Glucocorticoid metabolite concentrations, with pen mean as statistical units, were subjected to 172 one-way analysis of variance using the GLM procedure of SAS. Post hoc inspection of the 173 data revealed no effects of hybrid and the model included treatment only (CLS, RLS, CON).

\section{RESULTS}

\section{Plumage scoring}

\section{Effects of method, team and genotype}

178 Plumage scores were significantly higher for the wings and tail with the RLS method and for 179 the neck and tail by team A. Total scores were subsequently significantly higher for the RLS 180 method and team A (see Table 1). Significant interactions were found between method and 181 team for neck, wings and tail score (Table 1). Only neck score showed a significant main 182 effect of genotype, with LB and TS having slightly lower scores even though pair-wise 183 differences were not significant (Table 1). 


\section{Agreement between methods and teams}

188 In general, kappa and weighted kappa values between methods and teams for the total 189 plumage score ranged from 0.25 to 0.34 and all were significantly larger than zero (Table 2).

190 PABAK values for total scores were higher (0.35 to 0.55). Scoring the single body parts gave 191 excellent PABAK scores ranging from 0.75 to 0.97 , with a few (cloaca and breast) being 192 somewhat lower (0.73 and 0.40 respectively) (Table 2$)$. Kappa values for these body parts 193 were also low ( 0.38 and 0.18 respectively).

\section{Corticosterone metabolites}

198 Treatment had no overall significant effect on concentration of corticosterone metabolites, but 199 birds subjected to CLS tended to excrete more corticosterone metabolites $2 \mathrm{~h}$ after scoring 200 compared with birds in $\mathrm{CON}(158 \pm 25 \mathrm{ng} / \mathrm{ml} v s .88 \pm 25 \mathrm{ng} / \mathrm{ml}, P=0.19)$. Concentrations 201 were intermediate after the RLS method $(137 \pm 36 \mathrm{ng} / \mathrm{ml})$.

\section{DISCUSSION}

204 The results showed that it is possible to obtain good precision by scoring birds at a distance 205 compared with catching them and scoring while handling. Furthermore, we found that 206 adrenocortical activity tended to be highest when birds were scored after catching and 207 handling, intermediate when scored at a distance, and lowest when not scored at all.

208 RLS scored significantly higher on all body parts than CLS. The same finding (RLS 209 scoring lower damage than CLS) was reported by Bright et al. (2006). It makes sense that 210 more damage is recorded when (1) birds are closely inspected (handled) and (2) when the 211 number of body parts scored increase. In addition, teams scored significantly differently. This 
212 is a well known risk and the effect is normally balanced and included in the statistical models 213 used.

214 Agreement between teams using the CLS method, based mainly on PABAK scores, 215 were high for total plumage scores and excellent for single body regions, except for the breast 216 and cloaca. These findings are comparable to those found when validating the original version 217 of the LayWel scoring system (Tauson et al., 1984) and other plumage scoring systems 218 (Adams et al., 1978; Bright et al., 2006). Interestingly, the somewhat lower agreement 219 between teams within CLS for the body parts breast and cloaca indicates that these body parts 220 are more difficult to score and special attention should be given here during the introduction 221 and training phase for scoring teams. Agreement was very high for the back score, which is 222 one of the most important areas for estimating the extent of feather pecking in the flock.

223 Our data support and extend those of Bright et al. (2006), who compared handling vs. 224 scoring at a distance using a scoring method (Bilcík and Keeling, 1999) only slightly different 225 to the one used in the present study. The two methods (handling vs. distance) used by Bright 226 et al. (2006) were found to be significantly correlated. However, there was a potential risk of 227 recapture in the investigation of Bright et al. (2006), thus possibly inflating the correlation. In 228 the present study this problem was overcome by the experimental design.

229 To our knowledge, this is the first study to investigate the potential of plumage scoring 230 to elicit physiological stress responses. The differences $(45-65 \mathrm{ng} / \mathrm{g})$ in corticosterone 231 metabolite concentrations between controls and treated birds were smaller than those reported 232 by Janczak et al. (2007), who found elevations of between 100 to $250 \mathrm{ng} / \mathrm{g}$ faecal 233 corticosteroid metabolites when unpredictable feeding schedules were applied to hens. 234 Baseline levels were very similar in the present experiment to those of Janzak et al. (2006), 235 even though, among other things, genotypes differed (White Leghorns vs. medium-heavy 236 strains). This is in accordance with findings of Fraisse and Cockrem (2006), who found no 
237 differences in baseline concentrations of plasma corticosterone, but different stress response 238 patterns between two layer strains. Contrary to Janzak et al. (2006), severe feather pecking in 239 young pullets did not induce any significant change in the concentration of corticosterone 240 metabolites in excreta (Riber et al., 2006).

241 In conclusion, a reduced version of the LayWel scoring system is a valid and reliable 242 scoring method which tends to induce less stress to the subjects than the original procedure. 243 The scores cannot, however, be expected to equal those obtained with the complete method.

\section{ACKNOWLEDGMENTS}

\section{REFERENCES}

249 ABRAHAMSSON, P. (1996) Furnished cages and aviaries for laying hens. Effects on 250 production, health and use of facilities. Dissertation. Report 234. Department of Animal 251 Nutrition and Management, Swedish University of Agriculture, Uppsala.

252 ADAMS, A.W., CRAIG, J.V. \& BHAGWAT, A.L. (1978) Effects of flock size, age at 253 housing, and mating experience on two strains of egg-type chickens in colony cages. Poultry 254 Science, 57: 48-53.

255 BILCÍK, B. \& KEELING, L. (1999) Changes in feather condition in relation to feather 256 pecking and aggressive behaviour in laying hens. British Poultry Science, 40: 444-451.

257 BYRT, T., BISHOP, J. \& CARLIN, J.B. (1993) Bias, prevalence and kappa. Journal of 258 Clinical Epidemiolgy, 46: 423-429.

259 BRENNINKMEYER, C., DIPPEL, S., MARCH, S., BRINKMANN, J., WINKLER, C. \& 260 KNIERIM, U. (2007) Reliability of a subjective lameness scoring system for dairy cows. 261 Animal Welfare, 16: 127-129. 
262 BRIGHT, A., JONES, T.A. \& DAWKINS, M.S. (2006) A non-intrusive method of assessing

263 plumage condition in commercial flocks of laying hens. Animal Welfare 15: 113-118.

264 CUNNINGHAM, M. (2009) More than Just the Kappa Coefficient: A Program to Fully 265 Characterize Inter-Rater Reliability between Two Raters. Paper no. 242-2009 in SAS Institute 266 Inc.: Proceedings of the SAS®Global Forum 2009 Conference (Cary, NC, SAS Institute 267 Incorporated).

268 FLEISS, J.L., LEVIN, B. \& PAIK, M.C. (1993) Statistical methods for rates and proportions, 269 3rd edition (New York, John Wiley \& Sons). Cit. from BRENNINKMEYER et al. (2007).

270 FRAISSE, F. \& COCKREM, J.F. (2006) Corticosterone and fear behaviour in white and 271 brown caged laying hens. British Poultry Science, 47: 110-119.

272 GUNNARSSON, S. (2000) Laying hens in loose housing systems. Thesis. Veterinaria 73, 273 Swedish University of Agriculture, Skara.

274 GUNNARSSON, S, ODÉN, K., ALGERS, B., SVEDBERG, J. \& KEELING, L. (1995) 275 Poultry health and behaviour in a tiered system for loose housed layers. Report no. 35. 276 Swedish University of Agriculture, Skara.

277 HILL, A. (1980) Feather loss in layers. MAFF Poultry Booklet no.7, pp. 46-52. Gleadthorpe 278 Experimental Husbandry Farm.

279 HUGHES, B.O. (1982) Feather pecking and cannibalism in domestic fowls. Hohenheimer 280 Arbeiten: Disturbed Behaviour of Farm Animals, 121: 138-146.

281 HUGHES, B.O. \& DUNCAN, I.J.H. (1972) The influence of strain and environment upon 282 feather pecking and cannibalism in fowl. British Poultry Science, 13: 525-547.

283 JANCZAK, A.M., TORJESEN, P., PALME, R. \& BAKKEN, M. (2007) Effects of stress in 284 hens on the behaviour of their offspring. Applied Animal Behaviour Science, 107: 66-77.

285 KANNAN, G. \& MENCH, J.A. (1996) Influence of different handling methods and crating 286 periods on plasma corticosterone concentrations in broilers. British Poultry Science, 37: 21- 
28731.

288 KJAER, J.B. (2000) Diurnal rhythm of feather pecking behaviour and condition of 289 integument in four strains of loose housed laying hens. Applied Animal Behaviour Science, 290 65: 331-347.

291 LAYWEL (2005) http://www.laywel.eu.

292 LITTELL, R.C., MILLIKEN, G.A., STROUP, W.W. \& WOLFINGER, R.D. (1996) SAS

293 System for Mixed Models (Cary, NC, SAS Institute Inc.). ISBN 1-55544-779-1.

294 RETTENBACHER, S., MÖSTL, E., HACKL, R., GHAREEB, K. \& PALME, R. (2004)

295 Measurement of corticosterone metabolites in chicken droppings. British Poultry Science, 45: $296704-711$.

297 RETTENBACHER, S. \& PALME, R. (2009) Biological validation of a non-invasive method 298 for stress assessment in chickens. Berliner und Munchener Tierarztliche Wochenschrift, 122 : $299 \quad 8-12$

300 RIBER, A.B., PALME, R. \& FORKMAN, B. (2006) Effect of brooders on feather pecking 301 and cannibalism in domestic fowl (Gallus gallus domesticus). Applied Animal Behaviour 302 Science, 99: 287-300.

303 TAUSON, R. \& HOLM, K.-E. (2003) Evaluation of “Aviplus" - Big Dutchman - furnished 304 cage for 10 laying hens according to the $\$ 7$ in the Swedish Animal welfare Ordinance and 305 according to the New-Technique Evaluation Program at the Swedish Board of Agriculture. 306 Report 251. Swedish University of Agriculture, Uppsala.

307 TAUSON, R., AMBROSEN, T. \& ELWINGER, K. (1984) Evaluation of procedures for 308 scoring the integument of laying hens - Independent scoring of plumage condition. Acta 309 Agricultura Scandinavica, 34: 400-408.

310 TAUSON, R., KJAER, J.B., MARIA LEVRINO, G. \& CEPERO BRIZ, R. (2005) Applied 311 scoring of integument and health in laying hens. Proc. 7th European Symposium on Poultry 
312 Welfare, 15-19 June, Lublin, Poland. Polish Academy of Sciences 23(Suppl. 1): 153-159.

313 TAUSON, R., KJAER, J.B., MARIA LEVRINO, G., CEPERO BRIZ, R. \& HOLM, K.-E.

314 (2007) Applied scoring of integument and health in laying hens. URL:

315 http://poultry.huv.slu.se/hen/scoringsystem/scoringsystem.pdf. 


\begin{tabular}{|c|c|c|c|c|c|c|c|c|c|c|c|c|c|}
\hline \multirow{4}{*}{$\begin{array}{l}316 \\
317 \\
318 \\
319 \\
320\end{array}$} & \multicolumn{13}{|c|}{ Table 1. Plumage score (least squares means) for methods (CLS = complete LayWel scoring; $R L S=$} \\
\hline & & & & & hmann & Tradi & ion ar & $T S=$ & etra & & & & \\
\hline & Body part & & thod & $\mathrm{Te}$ & am & & Gen & ype & & & $P$ val & $\operatorname{tes}^{1}$ & \\
\hline & & CLS & RLS & A & B & IW & LB & LT & TS & Meth. & Team & $\mathrm{M} * \mathrm{~T}$ & Genotype \\
\hline 322 & Neck & 2.28 & 2.29 & 2.36 & 2.21 & 2.35 & 2.22 & 2.36 & 2.21 & $\mathrm{~ns}$ & $* *$ & * & $*^{2}$ \\
\hline 323 & Back & 3.68 & 3.77 & 3.71 & 3.74 & 3.62 & 3.68 & 3.76 & 3.84 & ns & ns & $\mathrm{ns}$ & ns \\
\hline 324 & Wings & 3.58 & 3.78 & 3.71 & 3.65 & 3.74 & 3.62 & 3.71 & 3.65 & $* * *$ & ns & * & ns \\
\hline 325 & Tail & 3.62 & 3.84 & 3.76 & 3.70 & 3.65 & 3.71 & 3.86 & 3.71 & $* * *$ & * & $* *$ & $\mathrm{~ns}$ \\
\hline 326 & Total (CLS & 13.2 & 13.7 & 13.5 & 13.3 & 13.4 & 13.2 & 13.7 & 13.4 & $* * *$ & $*$ & ns & ns \\
\hline
\end{tabular}

$1 *, * *$ or *** indicates a significant effect with $P<0.05, P<0.01$ or $P<0.001$ respectively

${ }^{2}$ After Tukey-Kramer adjustment for multiple tests, no pair-wise differences between genotypes were significant 
Table 2. Measures of agreement between methods $(C L S=$ Complete LayWel Scoring; RLS = Reduced LayWel Scoring) within teams (A and B) and between-teams within methods. SE(kappa), $Z$ and $P<|Z|$ are the asymptotic standard error, the standardised test statistic and the $P$ value of the two sided test of the simple kappa, respectively

$\begin{array}{lllll}\text { Comparison } & \text { Variable } & \text { Neck } & \text { Breast Back Wings Tail Cloaca } & \text { Total }^{1}\end{array}$

\section{Method CLS vs. RLS}

Within team A

Kappa
SE(kappa)
$Z$
$P<|Z|$
Weighted Kappa
PABAK
Kappa
SE(kappa)
Z
$P<I Z$
Weighted Kappa
PABAK

$\begin{array}{lllllll}0.59 & - & 0.62 & 0.51 & 0.23 & - & 0.28 \\ 0.05 & - & 0.05 & 0.05 & 0.05 & - & 0.04 \\ 11 & - & 13 & 10 & 5 & - & 9 \\ * * * & - & * * * & * * * & * * * & - & * * * \\ 0.63 & - & 0.70 & 0.54 & 0.26 & - & 0.52 \\ 0.84 & - & 0.90 & 0.84 & 0.75 & - & 0.47 \\ 0.69 & - & 0.74 & 0.45 & 0.32 & - & 0.34 \\ 0.06 & - & 0.05 & 0.05 & 0.05 & - & 0.04 \\ 13 & - & 16 & 9 & 6 & - & 11 \\ * * * & - & * * * & * * * & * * * & - & * * * \\ 0.73 & - & 0.79 & 0.53 & 0.40 & - & 0.61 \\ 0.94 & - & 0.95 & 0.78 & 0.77 & - & 0.53\end{array}$

Team A vs. B

Within method CLS

$\begin{array}{llllllll}\text { Kappa } & 0.60 & 0.18 & 0.78 & 0.72 & 0.64 & 0.38 & 0.25 \\ \text { SE(kappa) } & 0.05 & 0.04 & 0.05 & 0.05 & 0.05 & 0.06 & 0.03 \\ Z & 11 & 5 & 15 & 13 & 12 & 6 & 11 \\ P<|Z| & * * * & * & * * * & * * * & * * * & * * * & * * * \\ \text { Weighted Kappa } & 0.64 & 0.41 & 0.83 & 0.76 & 0.69 & 0.42 & 0.61 \\ \text { PABAK } & 0.87 & 0.40 & 0.96 & 0.90 & 0.87 & 0.73 & 0.35\end{array}$


Within method RLS

\begin{tabular}{llllllll} 
Kappa & 0.44 & - & 0.78 & 0.59 & 0.34 & - & 0.33 \\
SE(kappa) & 0.06 & - & 0.05 & 0.06 & 0.07 & - & 0.04 \\
$Z$ & 9 & - & 15 & 10 & 6 & - & 9 \\
$P<|Z|$ & $* * *$ & - & $* * *$ & $* * *$ & $* * *$ & - & $* * *$ \\
Weighted Kappa & 0.51 & - & 0.82 & 0.62 & 0.42 & - & 0.59 \\
PABAK & 0.79 & - & 0.97 & 0.90 & 0.88 & - & 0.55 \\
\hline
\end{tabular}

${ }^{1}$ When comparing CLS with RLS the total score includes 4 body parts only (neck+back+wings+tail) 